\title{
التحرش الجنسي بالمرأة العاملة
}

\author{
منى صالح النادر \\ محاضر بقسم الدراسات الاجتماعية كلية الآداب جامعة الملك سعود
}


مما لا شك فيه أن المرأة تساهم كقوى بشرية تساعد على زيادة الدخل القومي للدولة وزيادة

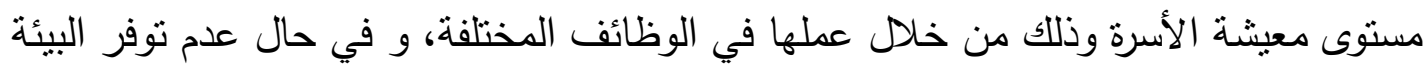

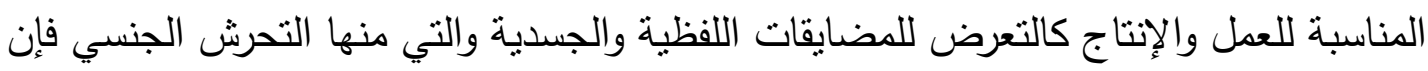

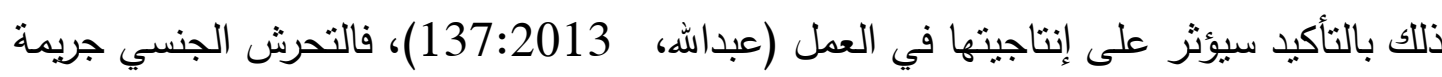

منتشرة في كافة أنحاء العالم، ولكنها بدأت نتزايد بحدة في كثير من مجتمعاتتا العربية ويحدث اعثيد التحرش غالباً من رجل في موقع القوة بالنسبة للأنثى أو للطفل، منل المدرس والتلميذة، الطبيب التهاء

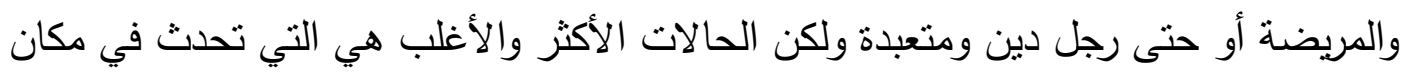

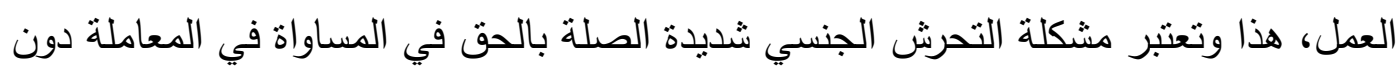

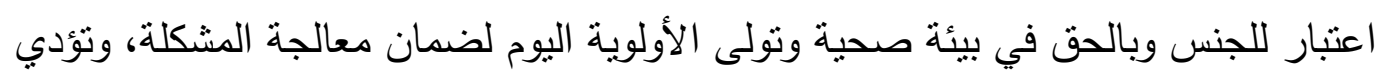

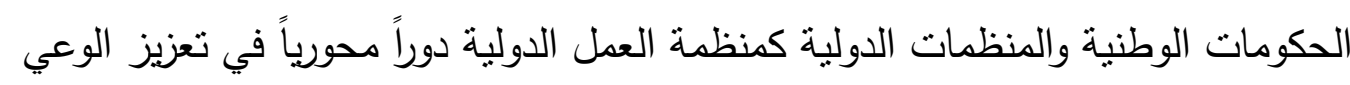

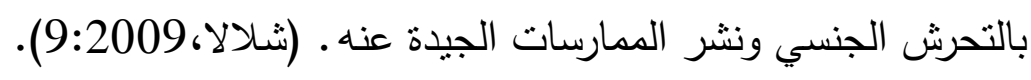

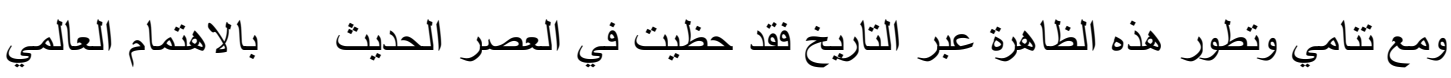

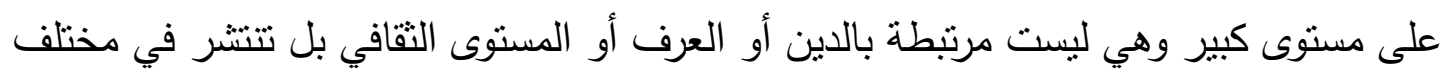

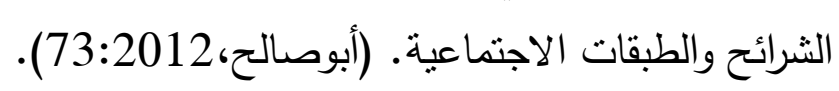

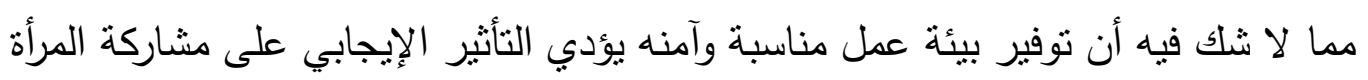

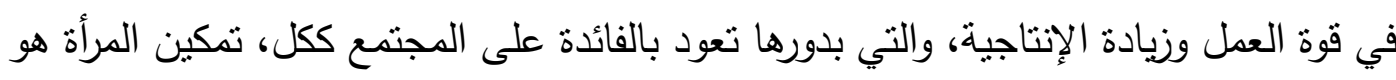

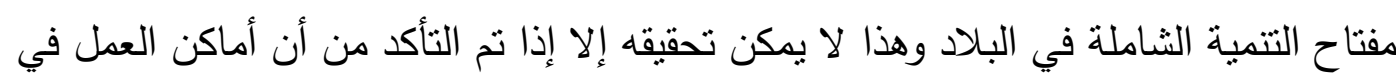

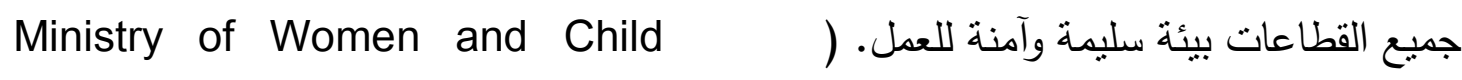
.2015،Devlopment

وقد نزايد الاهتمام منذ مطلع السبعينات بقضايا المرأة وشؤونها لضرورة دمجها في الحياة

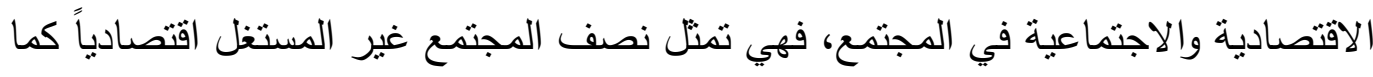

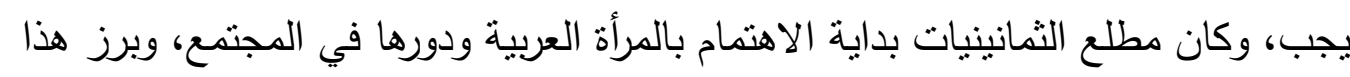
الاهتمام بوضوح في التسعينات من خلال المطالبة بالمساواة والعدالة. (عامر ، 2014:104). تاريخ ظهور مصطلح التحرش الجنسي:

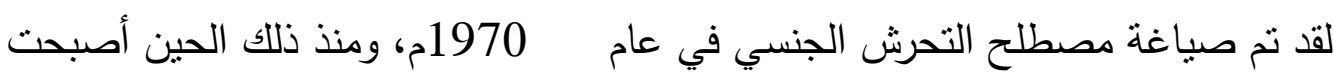

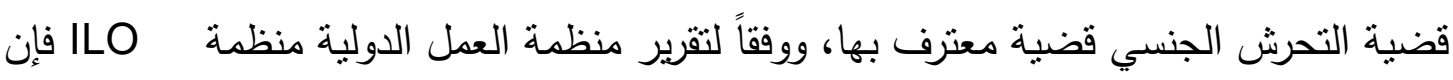

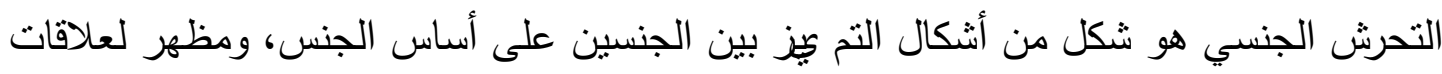


القوة غير المتكافئة بين الرجل والمرأة، والمشكلة لا تتعلق فقط بالاختلافات البيولوجية بين الرجل

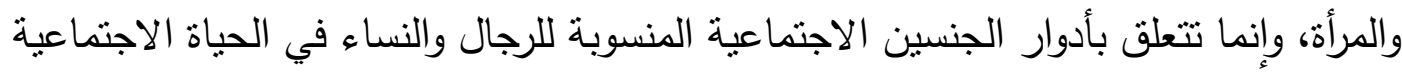

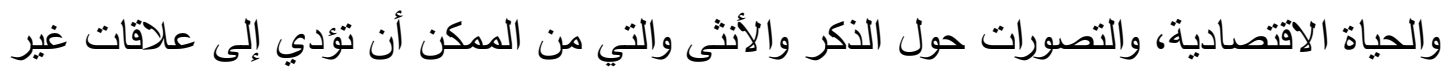

منوازنة القوة بين الذكور والإناث (Aware,2008:7). ويرجح البعض أن هذا المصلح ظهر عام 1975م على بلى يد ثمانية من الناشطات في أثناء

أحد اجتماعاتهن لتبادل الأفكار حول الكتابة على الملصقات عن المضايقات الجنسية الآتي

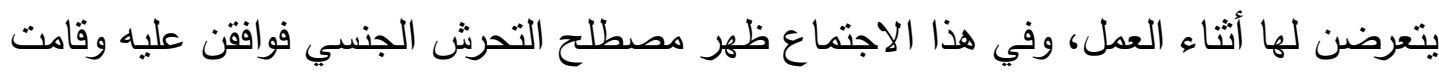
هؤلاء النانطات بتأسيس معهد السيدات العاملات وتزامن ذللك مع ظهور التحالف ضداع ضد الإكراه الجنسي الذي تأسس عام 1976م على يد النانطات فريدا كلين ولين رولي وإليزبيث كوهين هؤلاء برجع لهن الفضل في ظهور مص طلح التحرش الجنسي في السبعينات من القرن الماضي ولي ولئي (فرج، (19:2011).

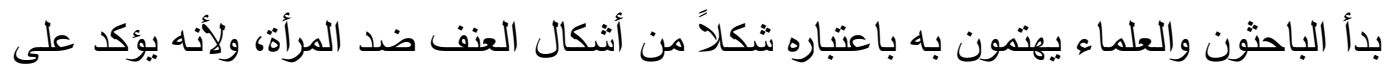

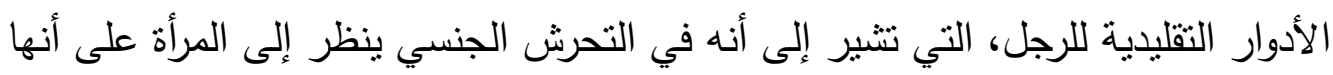

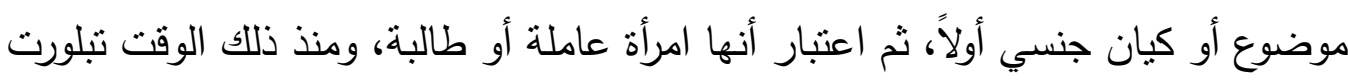

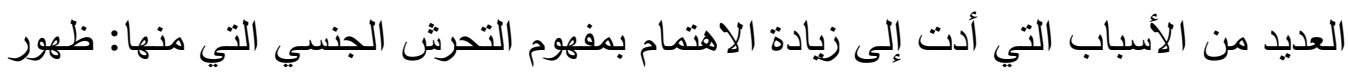

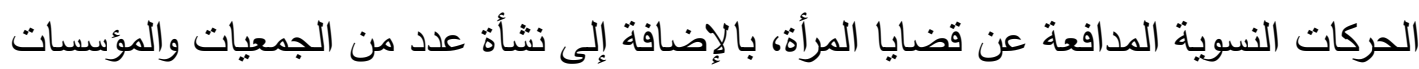

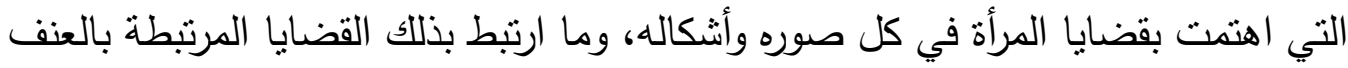

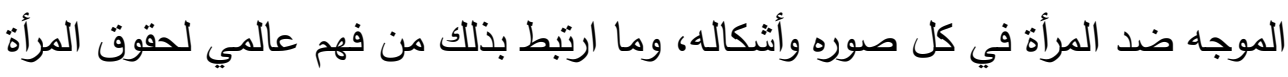

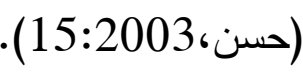

\section{مفهوم التحرش الجنسي في مجال العمل:}

لكل مجتمع مجموعة من التصورات عن ماهية التحرش الجنسي والتي تختلف بين المجتمعات،

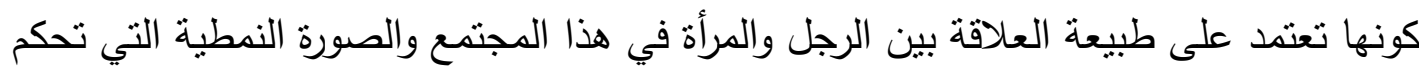
تلاك العلاقة؛ لذا من الصعب وضع قائمة بالسلوكيات التي تعد تحرشاً لكل المجتمعات الإنسانية،

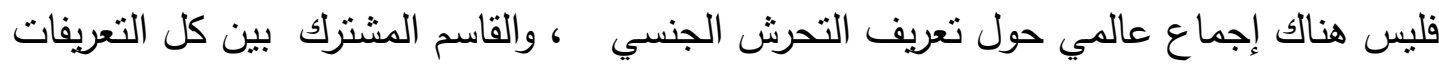
والأكثر أهمية كونها أنه غير مرغوب فيه و غير مرحب بعربه من قبل المستلم، هذا هو ما يميزها عن السلوك الودي المنقبل.

ويمكن القول أن التعريف الأكثر شيوعا يأتي من مجلس المفوضية الأوربية القرار 1990

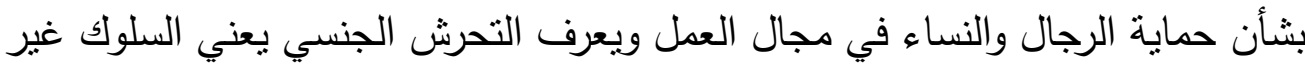


المرغوب به وله طبيعة جنسية، أو سلوك قائم على أساس الجنس، مما يؤثر على كرامة المرأة والرجل ويمكن أن يشمل سلوكيات لفظية وغيراللفظية. (Aware,2008:15). التحرش الجنسي قضية عامة وليست خاصة، كونها تؤثر سلباً على تتمية المجتمع وتطوره،

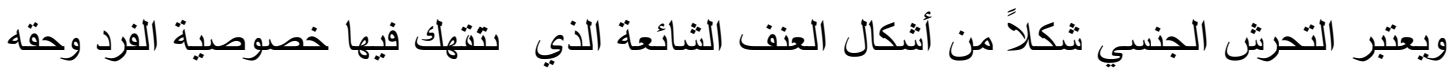

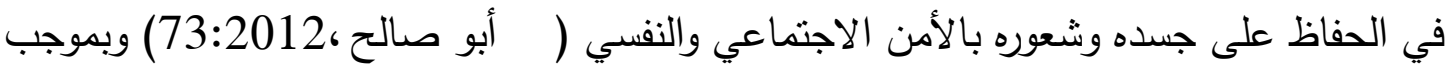

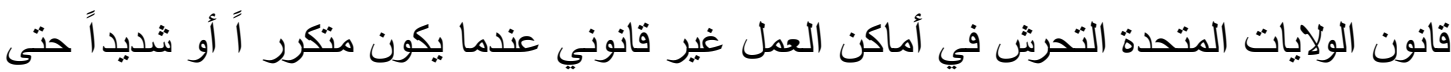

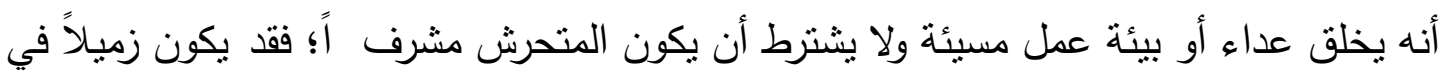
العمل أو من العملاء. (Human rights,2012).

تعود جذور مشكلة التحرش الجنسي في العمل إلى عوامل اقتصادية واجتماعية وتقافية متعددة وتختلف حسب طبيعة المكان الذي يمارس فيه العمل ونوع العمل وبيئة العلم، وقد تتعرض المرأة العاملة للتحرش الجنسي في مكان العمل من قبل رؤسائها مستخلين سلطتهر

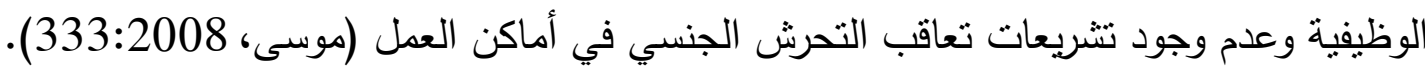

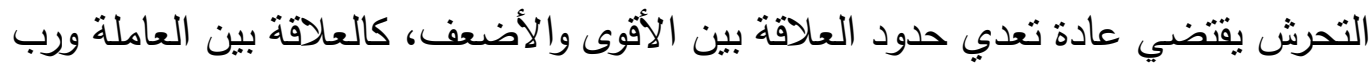
العمل، والتحرش إيذاء الإنسان على المستوى النفسي والجسدي من خلال الكلمات أو الأفعال الجنسية ويكون ذلك بعدم إرادة الإنسان أو بإرادته تحت ضغط (جمعة، 229:2013).

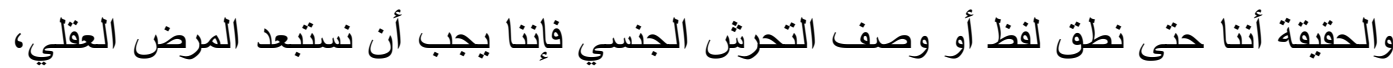

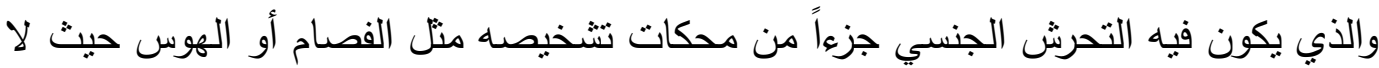
يكون المريض مسوؤل عن تصرفاته بما فيها التحرش الجنسي(السيد، 211:2012) يحدث التحرش الجنسي عادة من رجل في موقع قوة بالنسبة للأنتى متل الدرس والتلميذة والطبيب والمريضة أو حتى رجل دين ولكن الحالات الأغلب هي التي تحدث في مكان

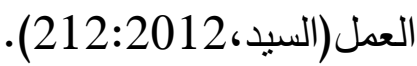

ويجب أن نشير إلى أنه من الصعب وضع تعريف محدد وشامل للتحرش الجنسي، إذ يعد

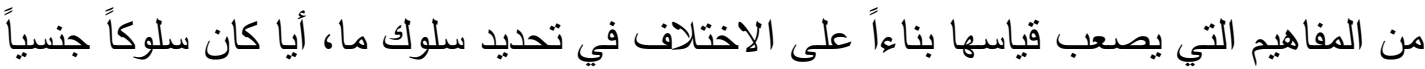
أو مجرد سلوك غير مرغوب فيه، مثال على ذلك عد الدعوات الاجتماعية على سبيل المنال تحرشاً أو لا، بسبب غموض أهداف الدعوات، إضافة إلى أن تصنيف بأنه تحرش أم لا يعتدد على الطرف المقابل، فهذه قضية نسبية بين الأفراد تعتمد على المنظومة القيمية ممنلة بالعادات

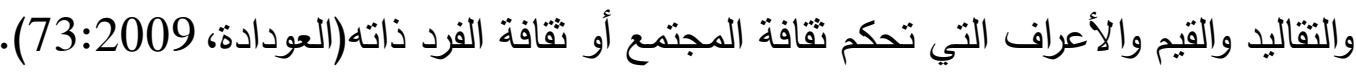
لا زال مفهوم التحرش الجنسي بشكل عام غير واضح في الدول العربية وبالأخص التحرش الجنسي في العمل نظراً لعدم سن قوانين واضحة بهذا الخصوص. 
واختلف تعريف التحرش الجنسي من باحث لآخر حسب مجال البحث، وهناك من اعنبر التحرش

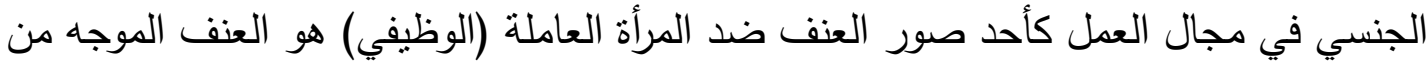
صاحب العمل ورب الأسرة والمجتمع، ويقوم على أساس التمييز الجنسي وعدم المساواة والعدل في الحقوق والواجبات ويترتب على ذللك أذى بدني ونفسي وجنسي وقانوني واقتصادي للمرأة. ويعرف العنف الموجه ضد المرأة كما ذكر في الدورة الحادية عشر ل

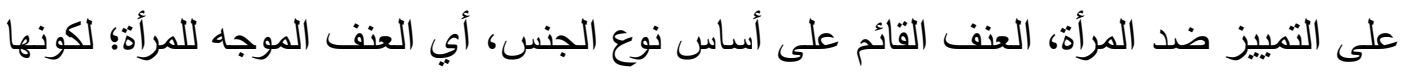

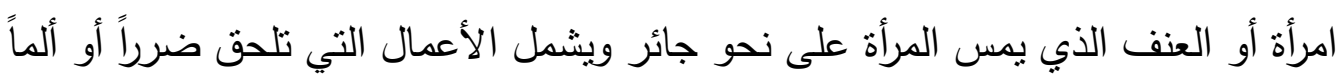

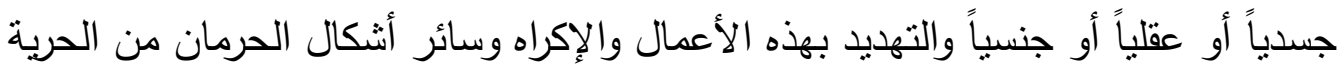
(عامر، (2014:109)

وقد عرفت رشا حسن التحرش الجنسي بالمرأة على أنه سلوك جنسي متعدد من قبل المتحرش غير مرغوب به من قبل ضحية المتحرش، حيث يسبب إيذاءً جنسياً أو نفسياً أو بدنياً

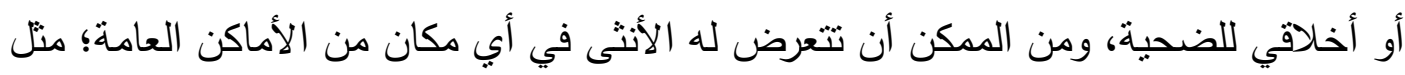

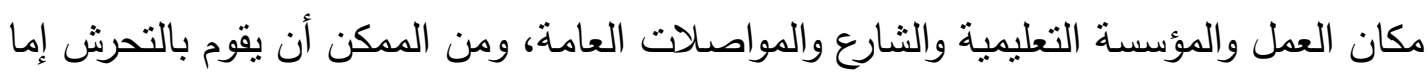

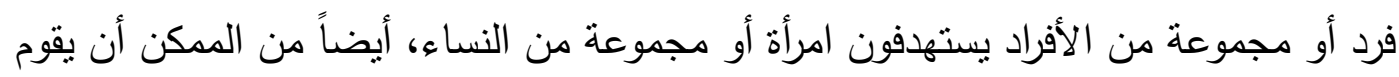

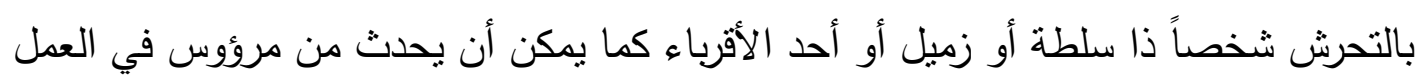

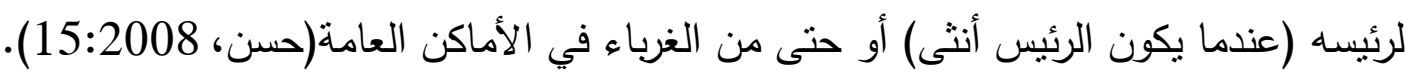

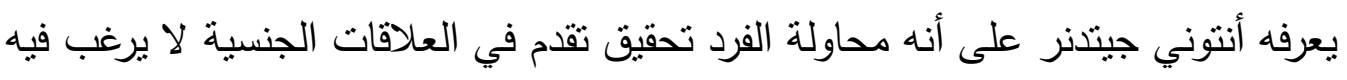

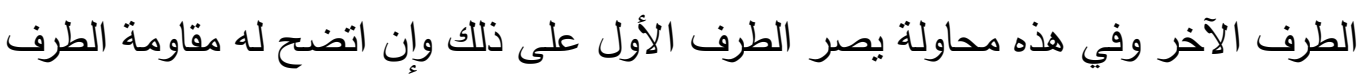
الآخر (جيدتز، 218:2006).

كما عرفه جوستان نيكولاس فيشر على أنه شكل خاص من أنكال العنف في مجال العمل، هذا

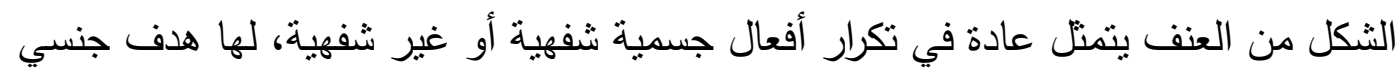
يمس حرية المرأة والرحل في العمل (ficher,2003:137). أشكال التحرش الجنسي:

من المكن أن يأخذ التحرش أثنكالاً عديدة أكثرها نعومة يبدأ بتوجيه مجاملة غير مرغوب بها

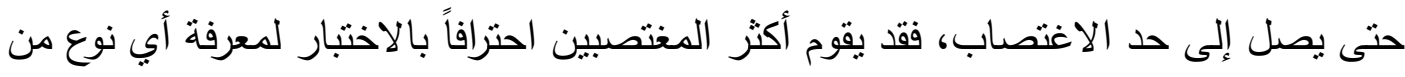
النساء تلك الضحية المستهدفة عن طريق تمرير صور من التحرش اللفظي أو اللمسات الخفيفة

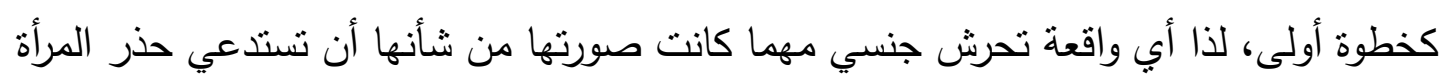
من إمكانية حدوث اغتصاب لها. تواجه المرأة في أماكن العمل أثنكالاً من التمييز والإيذاء، تتراوح بين التحرش الجنسي وعدم التهاب

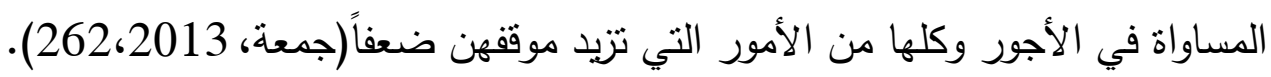


من ناحية أخرى فإن التحرش الجنسي الذي تتعرض له المرأة العربية في ميدان العمل قد

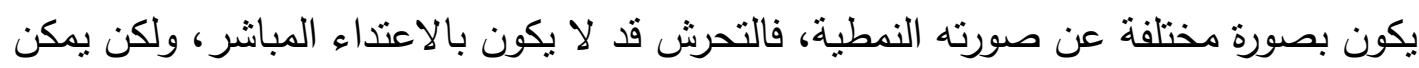
أن يكون عن طريق اللفظ أو النظرة أو الحركة(درويش، 2008:180).

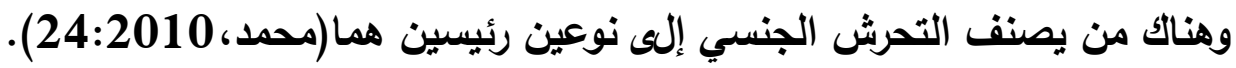

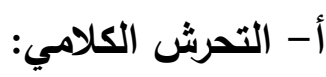

- نتعليقات ودعابات ، حركات، أصوات أو اقتراحات جنسية . - همسات بطريقة خادشة للحياء مع إصدار أصوات جنسية. - السؤال عن التخيلات الجنسية أو التفصيلات الجنسية أو الماضي الجنسية التهي. - إصدار تعليقات جنسية حول ملابس الجسم أو شكل أحدهم.

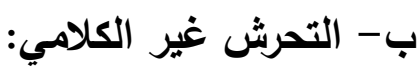

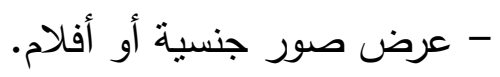

- - البريد الإلكتروني، الملصقات، الهدايا، المواد ذات الطبيعة الجنسية. - تخطي الحدود والمساحة الجسدية للآخر كالاقتراب منه أكثر من اللازم. - إجباره على التلفظ بألفاظ فاضحة. - تعابير وإيماءات بالوجه والغمز والنظرات الفاحصة. - القيام بحركات جنسية بواسطة اليد أو الجسد .

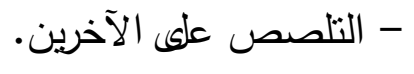

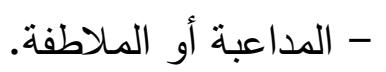

وهناك من قسم سلوكيات التحرش الجنسي (فرج، 39:2011) إلى:

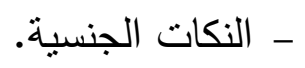

- الضغط على المجني عليها للخروج لموعد غرامي. - لفئل - الخطابات، والمحادثات والرسائل الهاتقية ذات الطبيعة الجنسية. - الإيماءات والنظرات التي تحمل معنى جنسي.

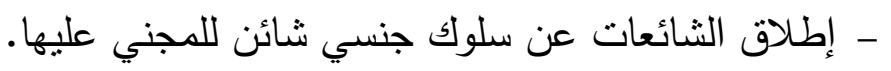
- شد ملابس المجني عليها.

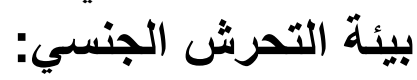
ييدو أن الظروف الحياتية الحالية تمثل ما يمكن أن نطلق عليه "بيئة محرضة على التحرش" ونذكر منها ما يلي: م الازدحام: 
هناك ما يسمى بالمساحة الحضارية لاى علماء الاجتماع وهي المساحة التي يتحرك فيها الفرد

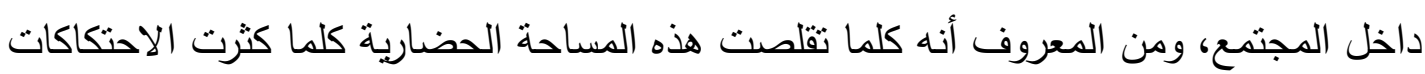
والمشكلات في التعامل بين الناس وزادت الميول العدوانهانية.

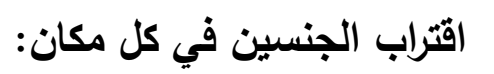

فنظراً لخروج الفتيات والنساء للاراسة والعمل فقد أصبح الحضور الأنثوي أحد مظاهر الحياة

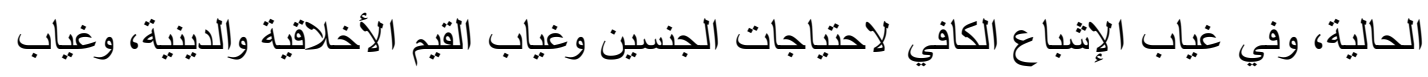
القوانين الرادعة يقع التحرش الجنسي.

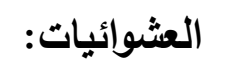

وهي بيئة تجمع بين الازدحام والفقر والحرمان والتلوث البيئي والأخلاقي؛ ولذلك فهي بيئة

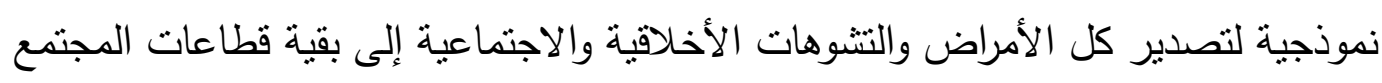
وطبقاته.

$$
\text { انتثار المسكرات والمخدرات: }
$$

وهي تساعد على إخماد قوى الضبط النفسي والأخلافي، وبالتالي تحدث لديه حالة من

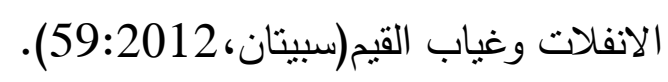

\section{ردود فعل المرأة نحو التحرش الجنسي في مجال العمل :}

الكثير من المتعرضات للتحرش الجنسي في العمل لا يتقدمن بالثكوى، بسبب الخوف من

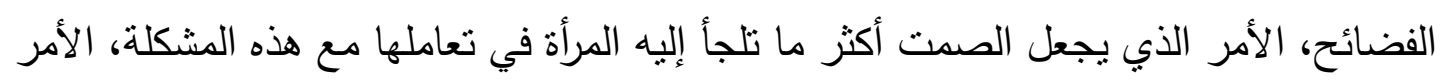

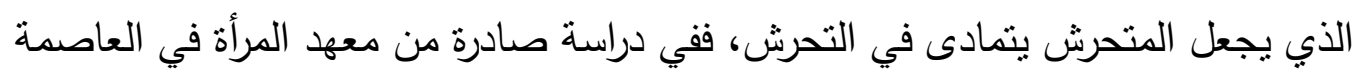
مدريد، أن عدد اللاتي يتجرأن على التقدم بشكوى لا يتجاوز

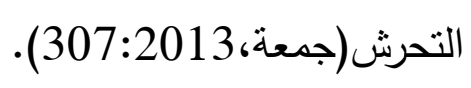

هذا ويحيط التحرش الجنسي اتجاهان يغذي كل منهما الآخر فمن جهة إنكار لوجود التحرش،

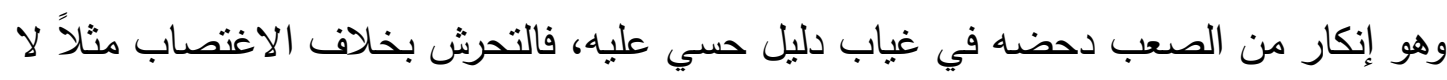

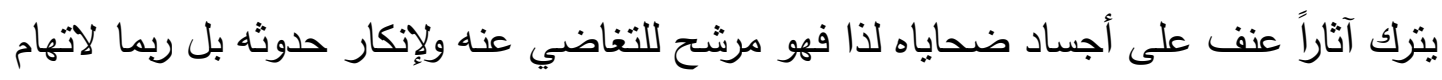

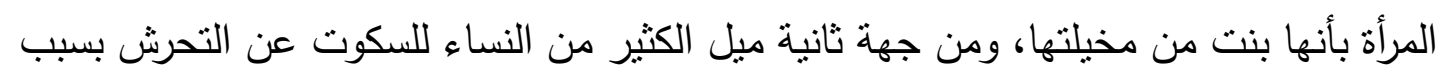

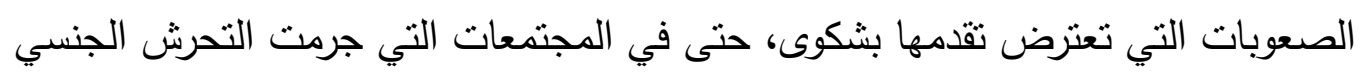

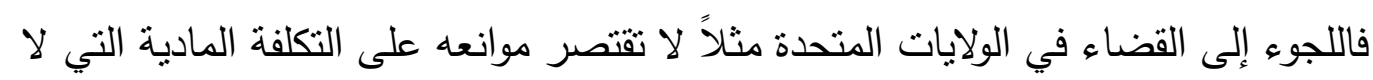

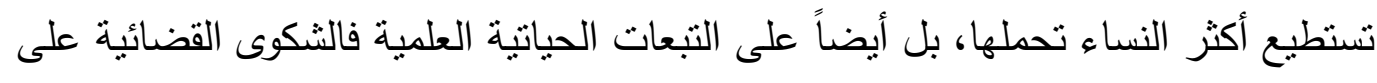

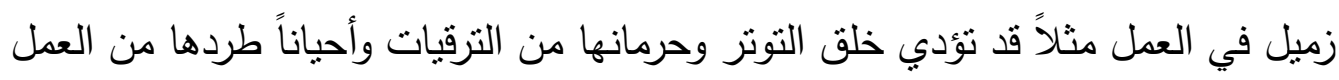
وبالأخص إذا كان المتحرش هو رب العمل (العمر، 165:2015). 


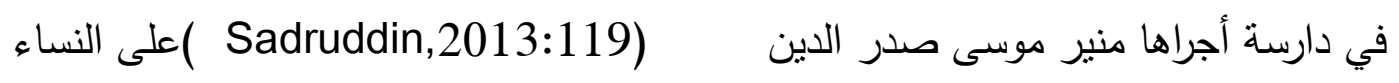
العاملات في باكستان اتضح أن ردود فعل النساء تتمحور غالباً حول ما يلي:

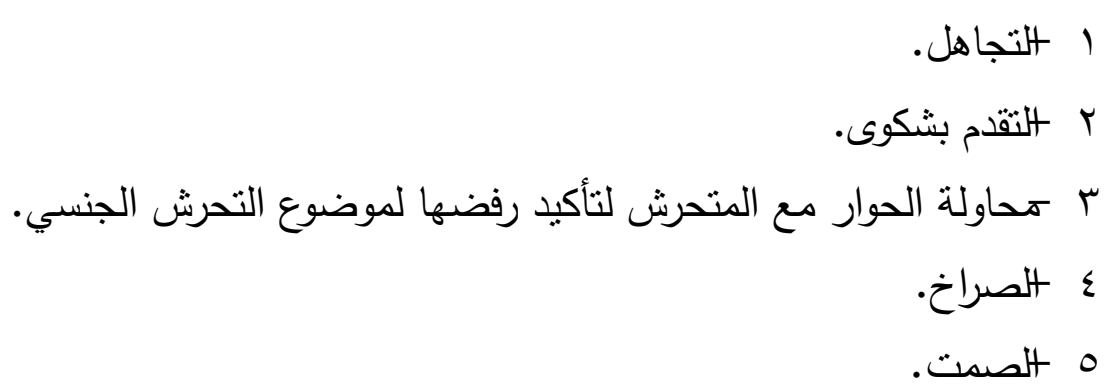

كثثرا ما تتخذ المرأة العربية موقف الصدت من حادثة التحرش كون المجتمع غالباً يرى أن المرأة

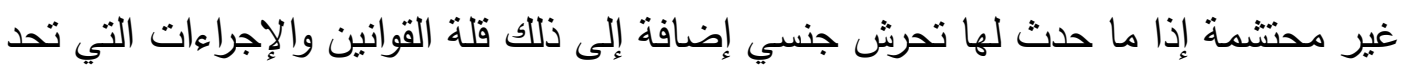

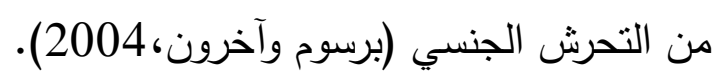
تفضل النساء اللجوء إلى الصدت بدلاً من مواجهة المتحرشين أو الإبلاغ عنهم؛ خوفاً من فقدان

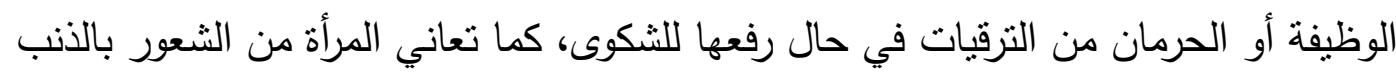

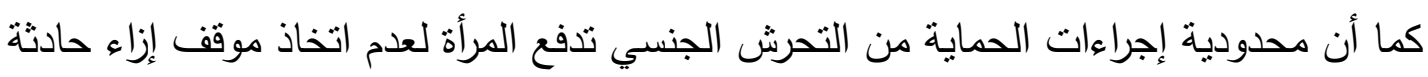
التحرش(Aware,2009).

برى (فرج، 40:2011) أن ردود فعل المجني عليها للتحرش في العمل تختلف بناءً على عدة

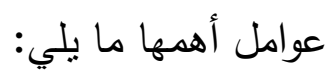

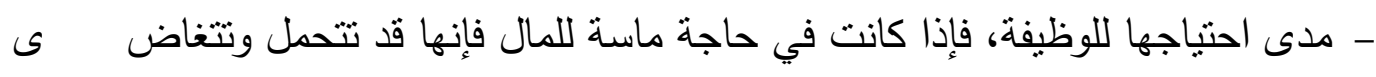

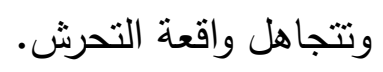

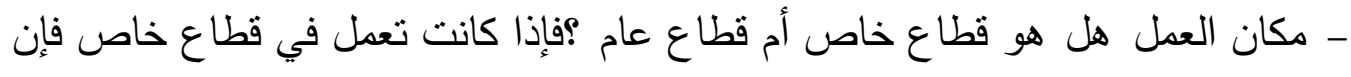

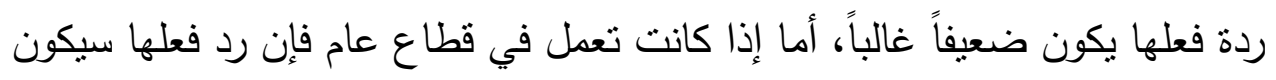
قوياً لأنها لا تخشى الإقالة.

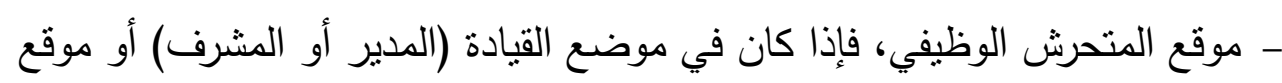

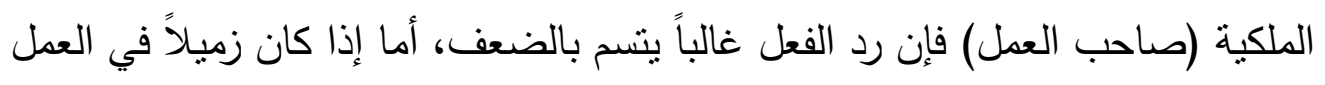
أي على نفس الدرجة الوظيفية للمجني عليها فإن رد فعلها غالباً سيكون قوياً . يمكن إرجاع علم إفصاح المرأة عن التحرش للأسباب التالية:

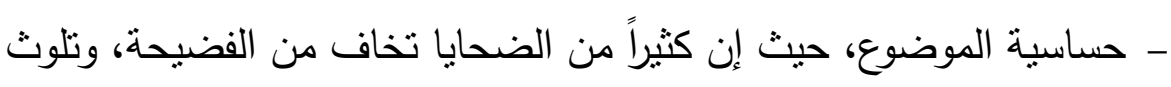

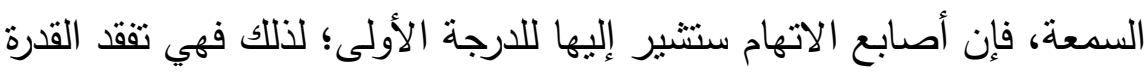
والثجاعة في التحدث عن معاناتها. - خوف الضحية من فقدان عملها.

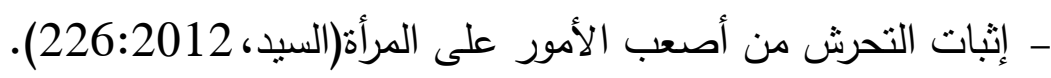


- اعتقاد الضحية أن الجاني لن يجد العقاب الرادع له مما ينسبب في تفاقم

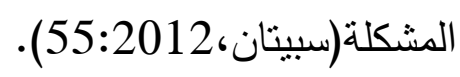

- كون التحرش له مساس بسمعة وشرف الأنثى فأنها لا تلجأ إلى البلاغ عما حصل لها؛ خوفاً من نظرة المجتمع.

- عدم ثقة الناس بالأجهزة الأمنية والنظام القضائي عند نظرها إلى المشكلات الأخلاقية

- عدم انحصار التحرش بشريحة عمرية واحدة، بل أكثر من ذللك عند الثباب

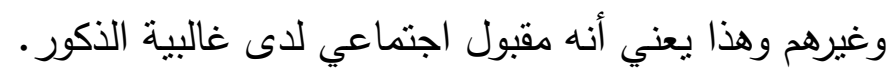

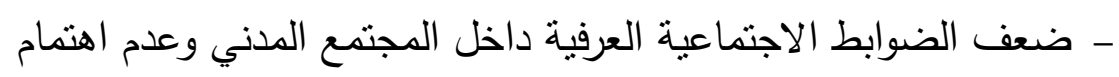
الضوابط الرسمية بها بشكل جدي (العمر ، 165:2015).

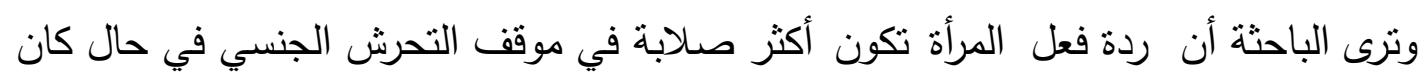

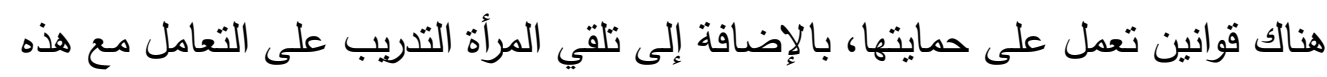

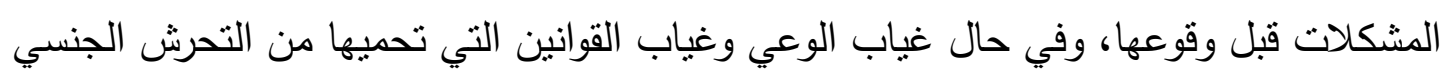

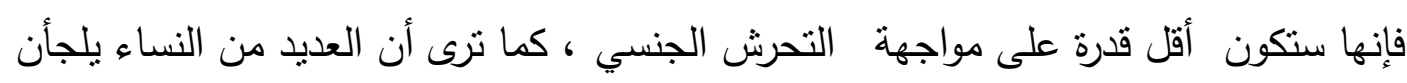

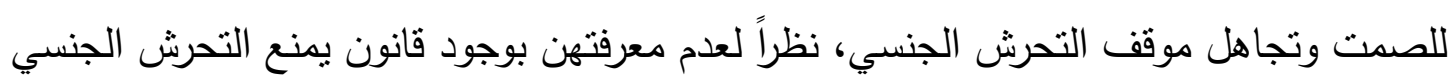

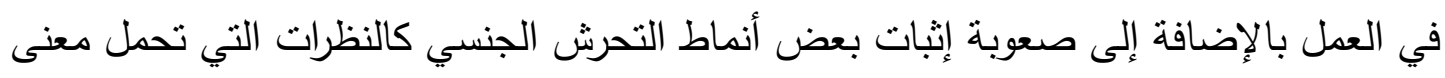

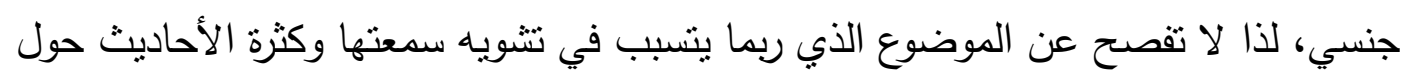
تصرفاتها وربما اتهامها في أخلاقياتها. دوافع التحرش الجنسي في العمل:

تميز الإنسان الطبيعي بحالة من النوازن بين الدوافع والضوابط، وهذا ما يجعله يتمكن من

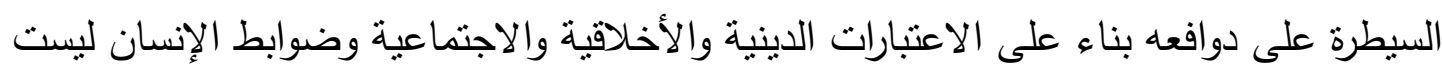

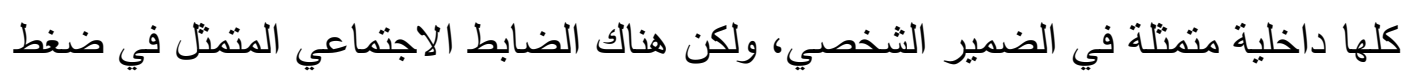

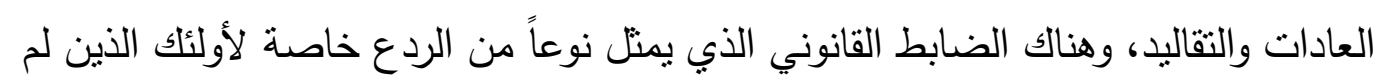

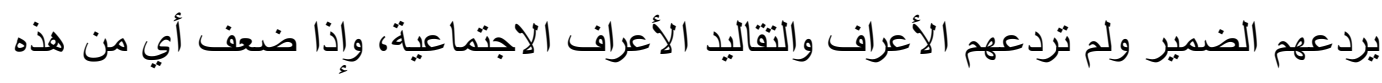
الضوابط أو ضعفت كلها، أو طغت الدوافع فإننا نتوقع خروج الرغبات (العدوانية والجنسية) متحدية ومهددة للسلام الاجتماعي(جمعة، 299:2013). يرجع التحرش الجنسي للعديد من الدوافع، أو قد يشبع عند صاحبه عدداً من الدوافع، ولكنه الاعبه

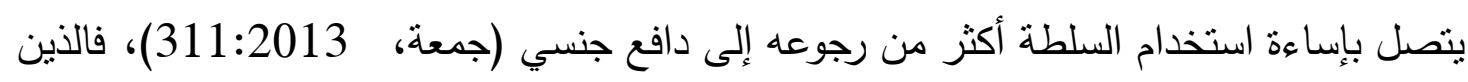

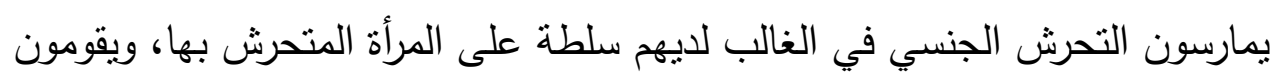

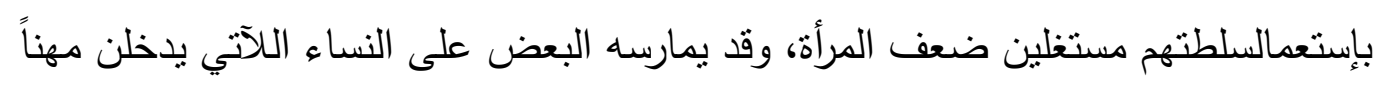


مخصصة للرجال، وذلك بغرض إبعاد المرأة عن منافسة الرجل في المهن التي يعتقد أنها تخصه

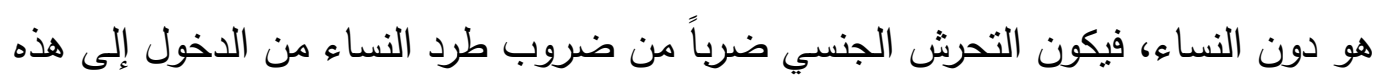

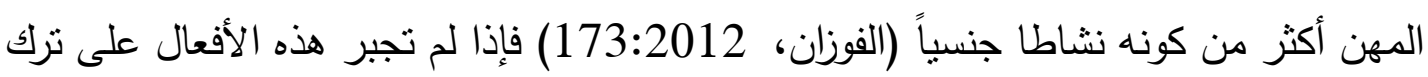

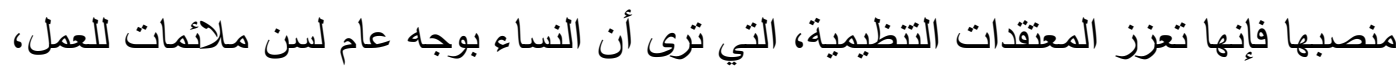

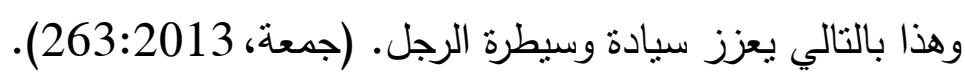

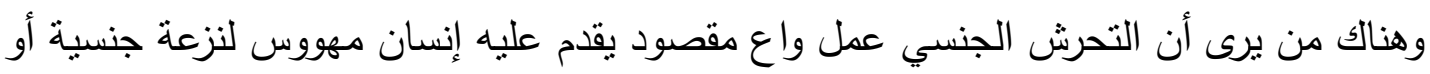

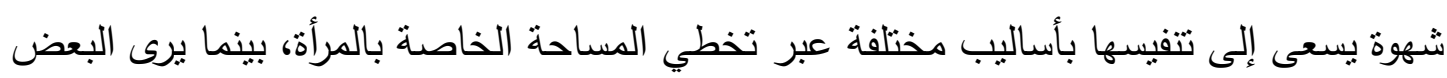

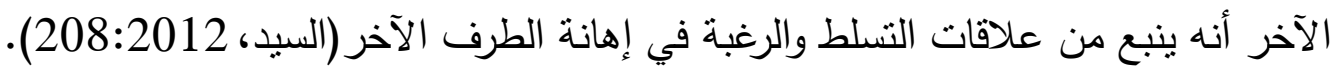

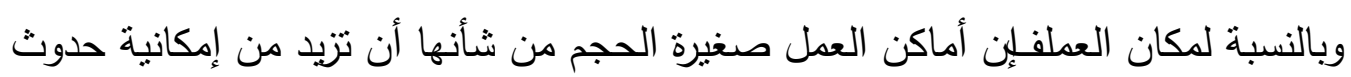

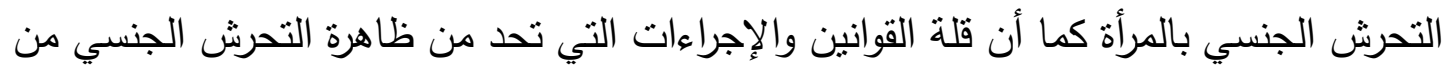
شأنها أن تضع المرأة في خطر أكبر (برسوم وآخرون، 2009).

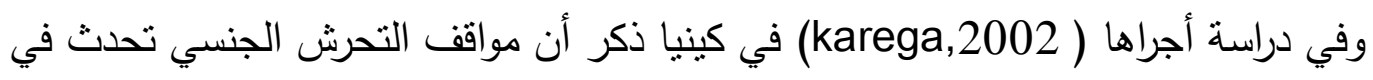

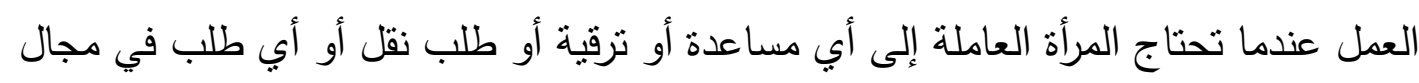
العمل، مما يجعل أصحاب العمل يستغلون الموقف في ابتزاز النساء لتلبية طلباتهم الجنسية.

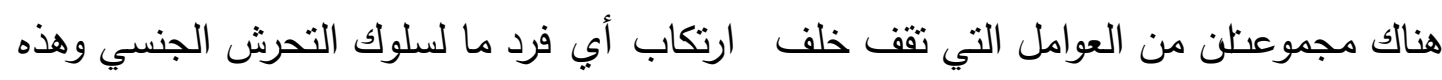
العوامل هي: العي مجرعن

ا - عوامل ذاتية: وهي مرنبطة بالفاعل نفسه وتتمتل في:

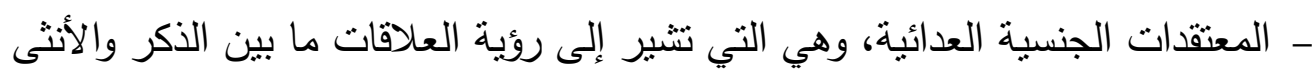

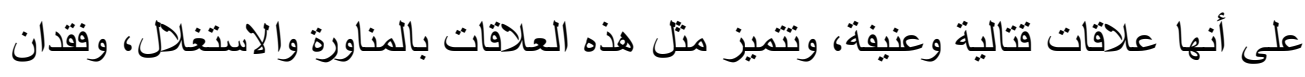
الثقة.

- المعتقدات الجنسية الخاطئة، والتي تساهم في تتويه الفعل الجنسي لاى الفرد، وهذ

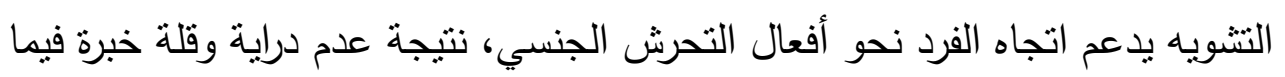
يرتبط بالثقافة الجنسية.

r t بلعوامل البيئية: وهي نتحصر في أن سلوك التحرش الجنسي يزداد داخل البيئة التي تصور وتعرض المرأة كأداة للجنس، وتدعم الاتجاهات التي تقلل من أهمية المرأة، وتبرز

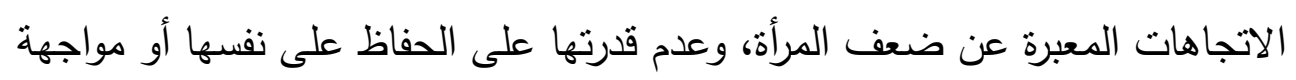

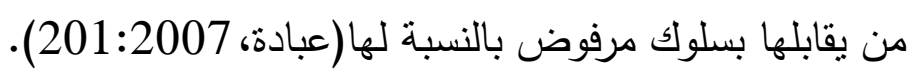

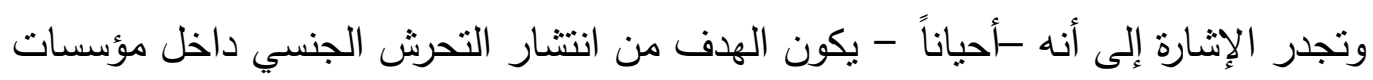

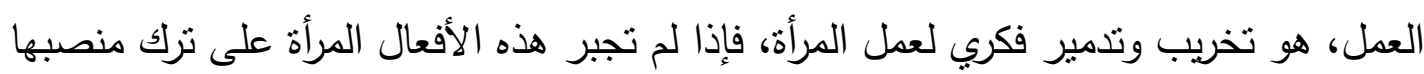


فإنها تعزز المعتقدات التتظيمية التي ترى أن النساء بوجه عام لسن ملائمات للعمل، وهذا بالتالي

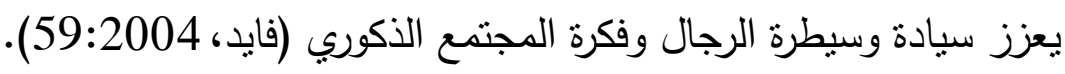
وهناك من أرجع أسباب التحرش الجنسي لما يلي:

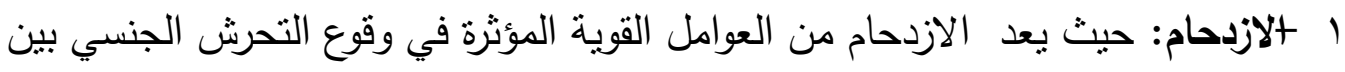
الجنسين وغالباً ما يكون ذلك في الأماكن التي ينوقع فيها الازدحام كالأسواق ووسائل

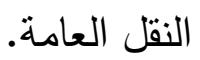

r +لاختلاط بين الجنسين: يسهم العمل المختلط والذي يكثر فيه الاحتكالك بين الجنسين في بروز مشكلة التحرش الجنسي.

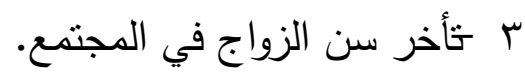

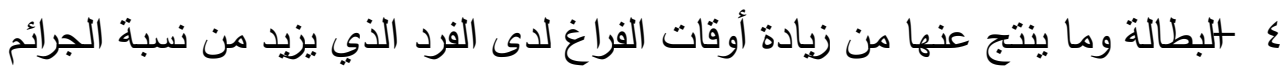

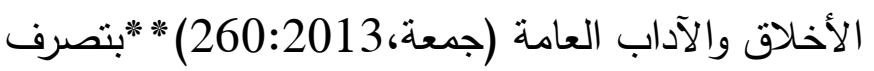

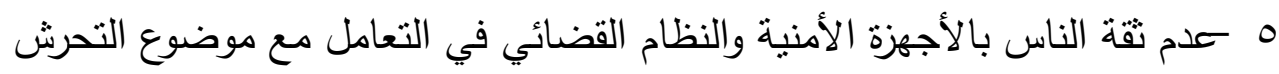
الجنسي في العمل(العمر، 163:2013). 7

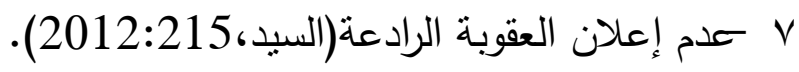

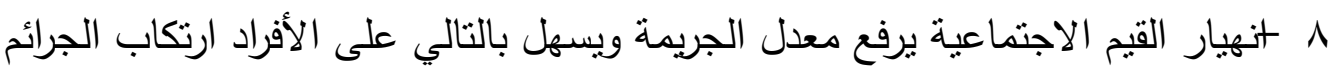

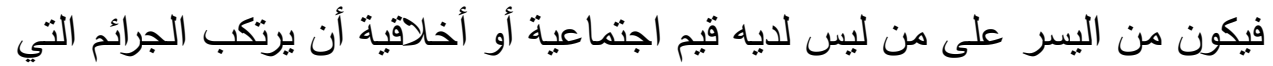

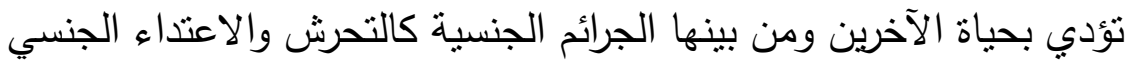

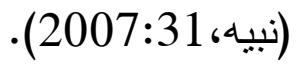

كما أكدت (عبادة، 2007:42) على أن أبرز أسباب التحرش الجنسي في مؤسسات العمل إلى إلى

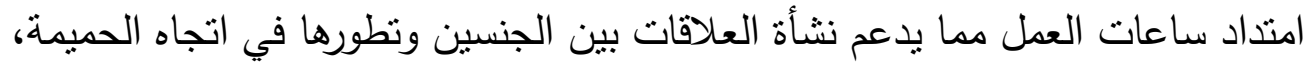

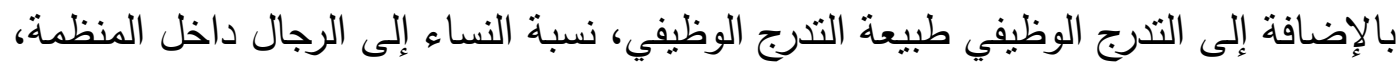

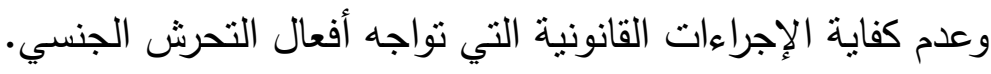

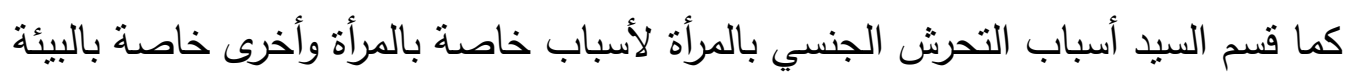
المحيطة

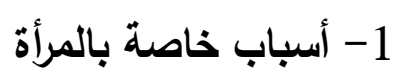

- عدم التزامها بالزي الملائم مما يعطي عنها فكرة الانحلال وأنها امرأة سهلة التعرض للتحرش

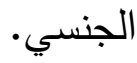
- سلبية المرأة التي تعرضت للتحرش الجنسي وعدم إبلاغها للجهات المختصة.

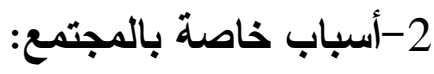


- التحرش موجود في كل مكان ولكن ربما تختلف الأسباب في المجتمع الغربي عنها في

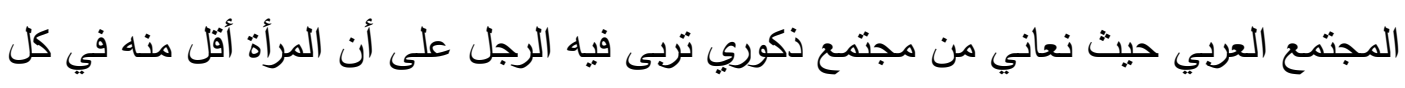
شيء. - ضعف الوازع الديني، البعد عن القيم والمبادئ الأخلاقية الفاضلة والعادات والتقاليد المحافظة - سيكولوجية التحرش العدوانية الانتهازي واستغلال الفرص.

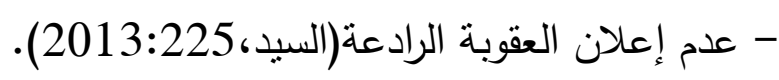
ولا نغفل أهمية الجوانب الإعلامية في ذللك حيث أثنار (عامر، 2014:130) إلى العى أن وسائل

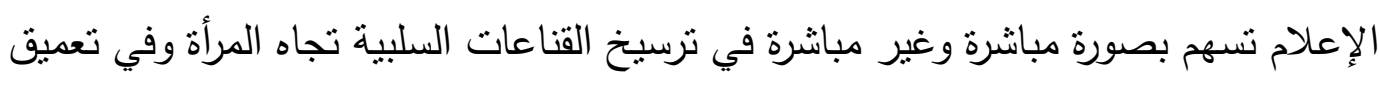

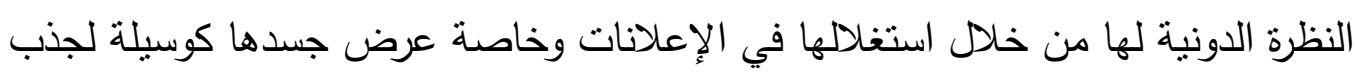
المشاهدين للاعاية والإعلان.

ووسائل الإعلام على اختلاف أنثالها تدعم استغلاد المرأة بشكل غير صحيح في البرامج

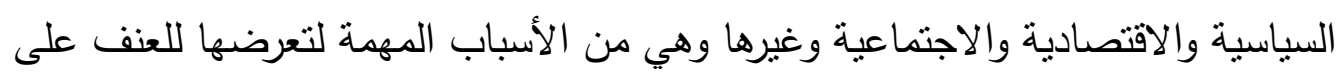

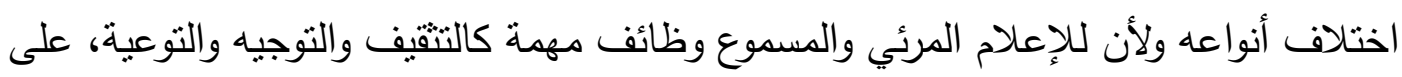

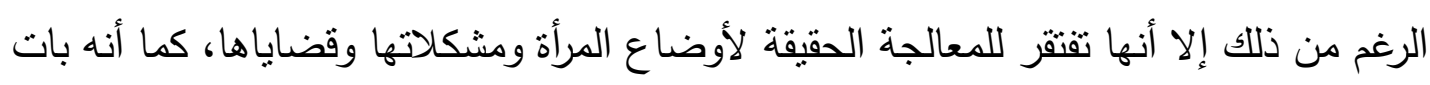

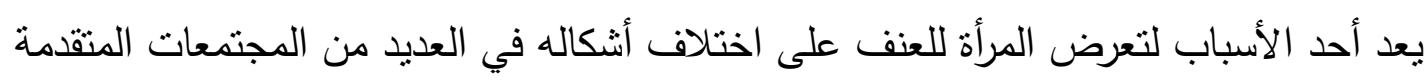

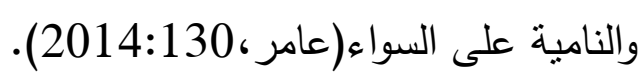
أما (Hersch,2015) فقد أثنار إلى أن احتمالية تعرض المرأة للتحرش الجنسي في عملها تزيد في عدد من الحالات وهي كما يلي:

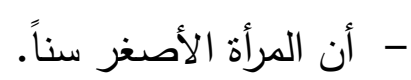

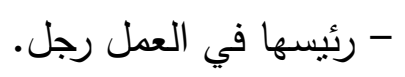

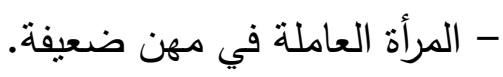

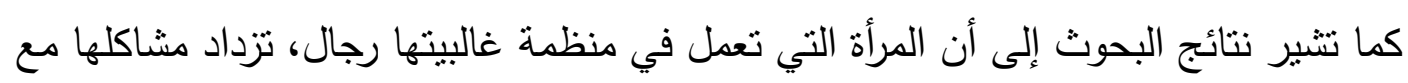

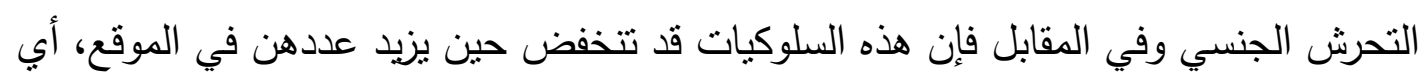

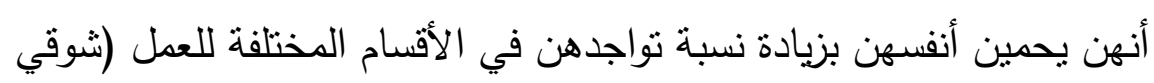

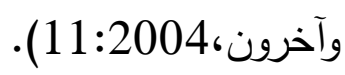
آثار التحرش الجنسي بالمرأة في مجال العمل:

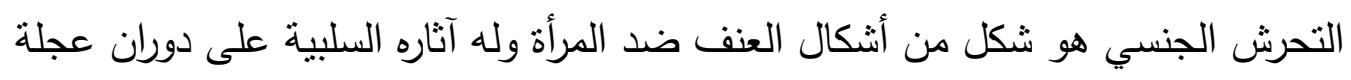
التتمية في الوقت الذي أصبح للمرأة دور مهم اً وفاعلاً في مشاركة الرجل في شتى التى مناحي الحياة (جمعة،270:2013) كما يؤدي بالمرأة إلى حالة من التتشت بين حاجتها للعمل من جهة فئ، وشعورها بالخوف من التحرش الجنسي سواء من العاملين أو العملاء. 
إن الافتقار إلى الضمان الاجتماعي وثغرة الأجور بين الجنسين وانخفاض الأجور بصورة عامة

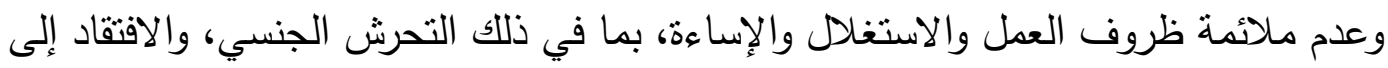
الصوت والتمثيل تفاقم مشكلات المرأة بسبب المسؤوليات الإضافية الناشئة عن دورها الإنجابي والافتقار إلى سبل الحصول على الموارد. والتحرش الجنسي وسائر أثنكال التحرش إنما هي أنثكال جسمية من التمييز في العالم تفوض الته كرامة المرأة والرجل وتبطل المساواة بين الجنسين ويمكن أن تخلف انعكاسات خطيرة. وينبغي حظر العنف القائم على أساس نوع الجنس في مكان العمل، كما ينبغي تتفيذ الجني

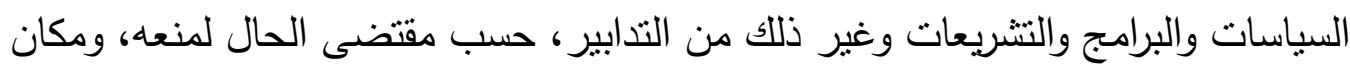
العمل هو موقع مناسب للوقاية من خلال تثقيف المرأة والرجل بثأن ما يعتبر طبيعة تمبيزية

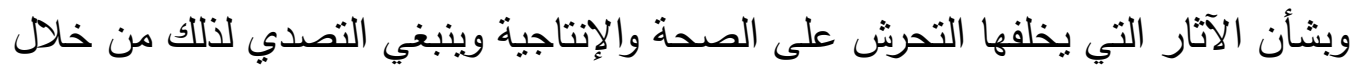

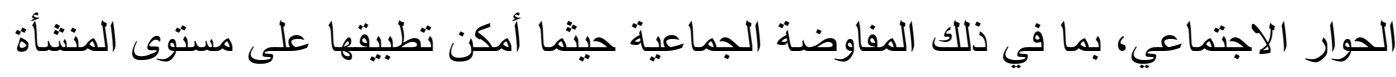
وعلى المستوى الوطني أو القطاعي(مكتب العمل الدولي، 2009). ويمكن تقسيم آثار التحرش الجنسي بالمرأة في مجال العمل فيما يلي: ا 1

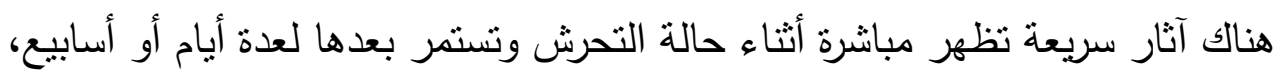

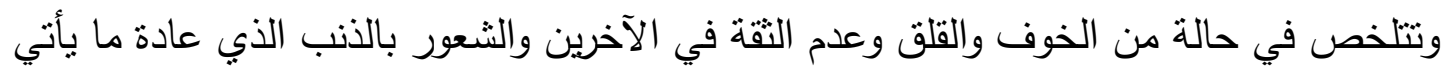

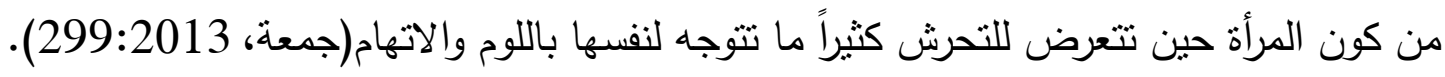

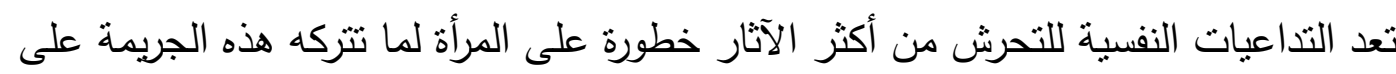

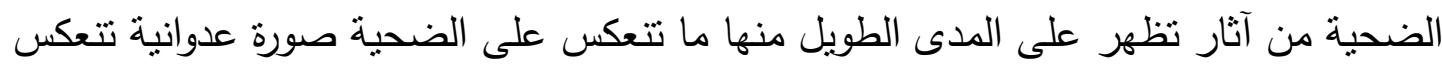

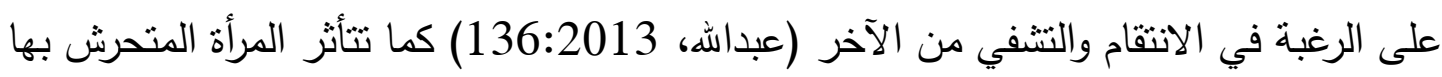

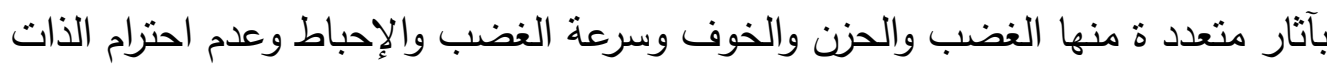

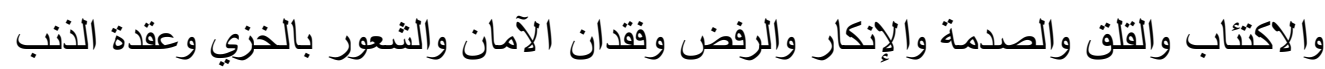

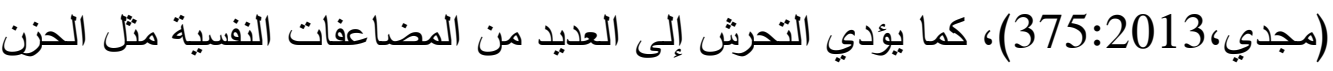

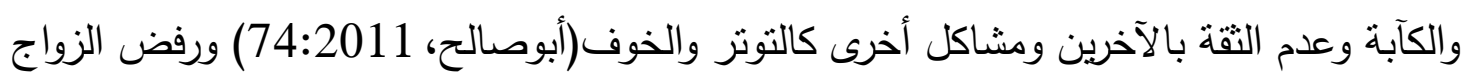

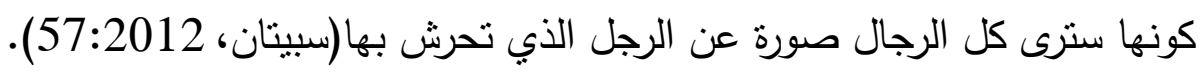
كما قد يولد التحرش الجنسي الثعور بالذل والإهانة.

\section{r - - ب آثار التحرش الجنسي على المرأة من الناحية البذنية:}

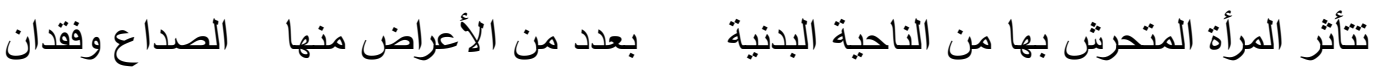

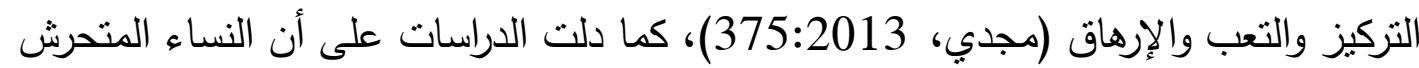

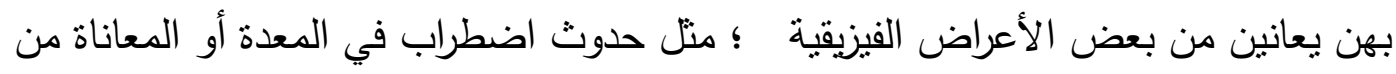


صعوبة في النوم وفقدان الوزن بالإضافة إلى صعوبات في تكيفهن الجنسي من ذلك فقدان الرغبة في الجنس (قطب، (تبا، 28:2008).

\section{r - - بآثار التحرش الجنسي على المرأة الناحية الاجتماعية:}

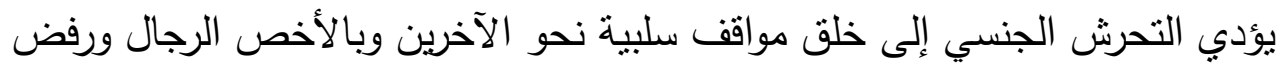

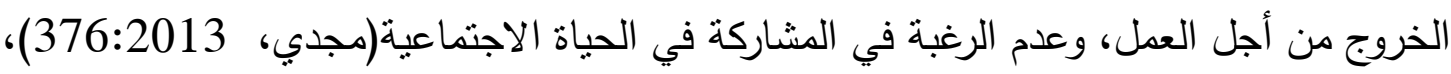
بالإضافة إلى الصعوبات التي تواجه المتحرش بها في علاقاتها الثخصية (قطب،

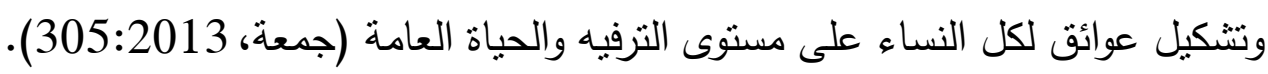
كما أن للتحرش الجنسي آثار بالغة الخطورة ليس فقط على المرأة بل على الأسرة والمحيطين

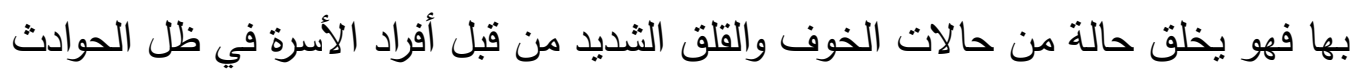

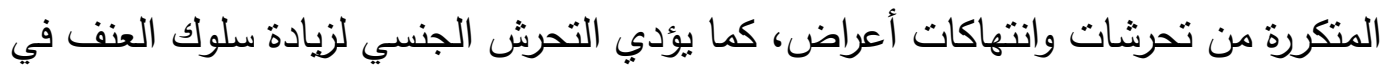

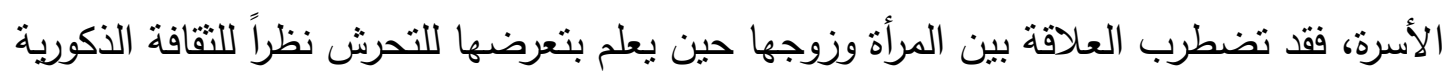

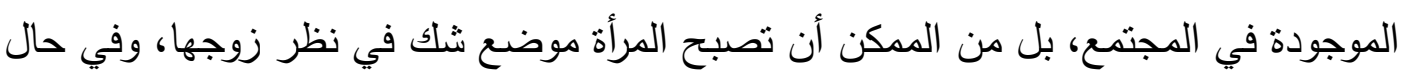

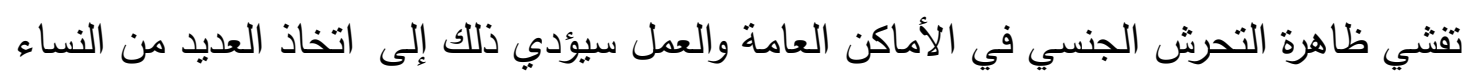

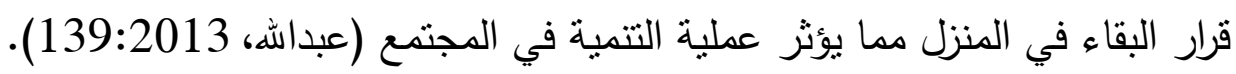
كما نرى أن لثقافة المجتمعات العربية بشكل عام دور كبير كونها تلقي باللوم على المرأة في حال

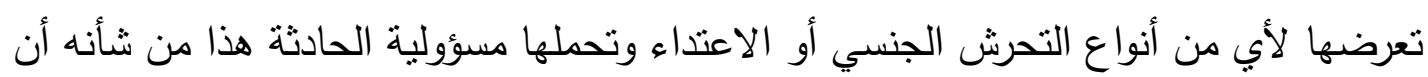

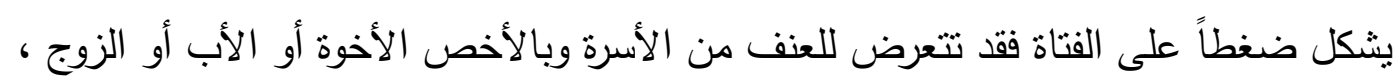

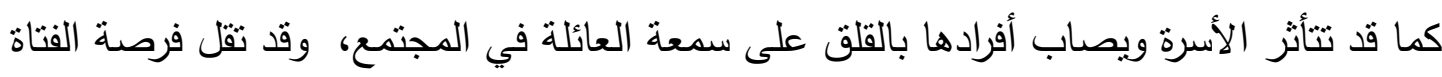
العزباء في الزواج نظراً لتعرضها للتحرش الجنسي في عملها وتكثر الأقاويل حول سلوكياتها.

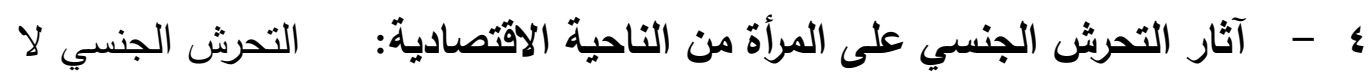

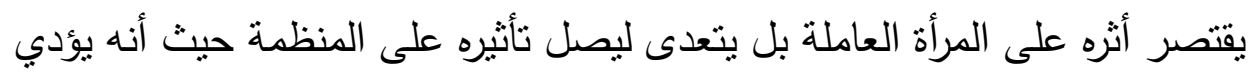

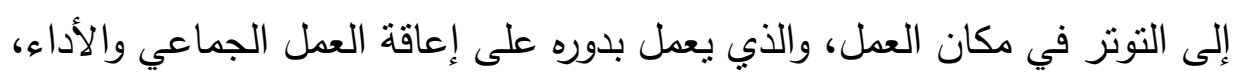

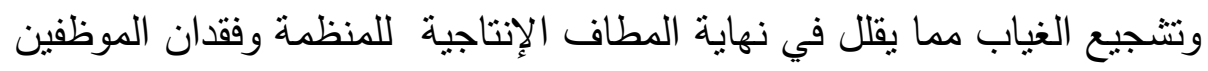

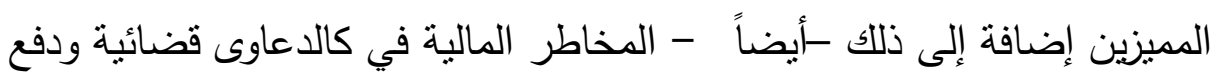

\section{تعويضات وغرامات(1): (Aware,2008).}

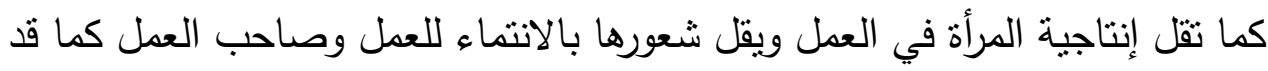

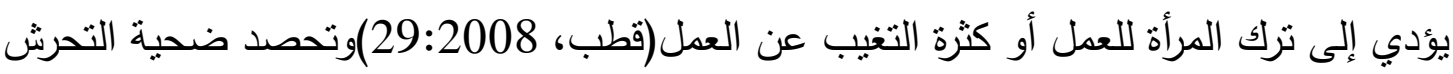

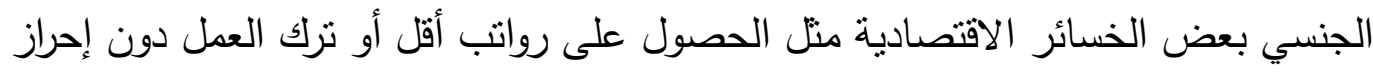

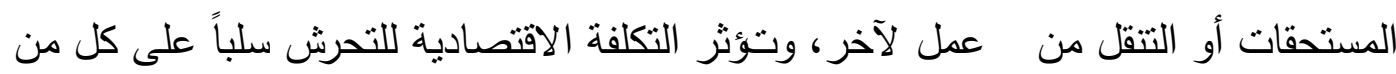


الموظفين والاقتصاد العالمي، حيث يسهم التحرش الجنسي في إحراز هذه الخسارة عن طريق خفض أو ضعف الإنتاج (عبداله، 137:2013).

كما يعمل التحرش الجنسي على الحد من قدرة المرأة على تطوير ذاتها ومهاراتها وإهدار

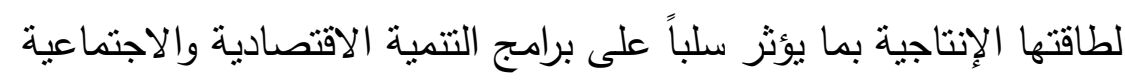
(موسى،333:2008) حيث يؤثر التحرش الجنسي على قدرة الضحية على الأداء في عملها

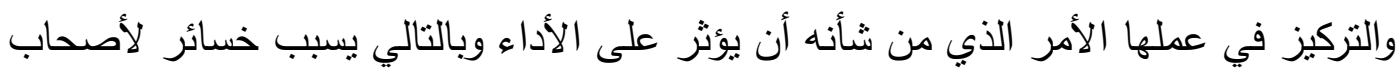
العمل.

كما تجدر الإثشارة إلى أن المرأة العاملة التي تنقدم بشكوى على المتحرش قد تكون عرضة

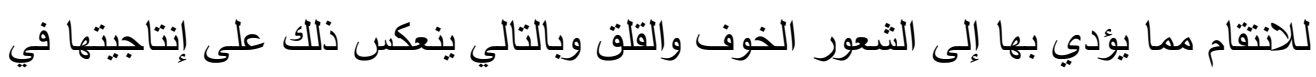
العمل(Bergman,2002).

لذا فشيوع التحرش في مكان العمل لا يقتصر تأثيره على المرأة المتعرضة للتحرش فهو

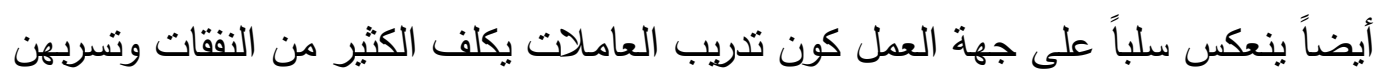
بسبب التحرش يدفع ثمنها صاحب العمل الذي يضطر للبحث عن بديلة و تدريبها من جديد وهذا

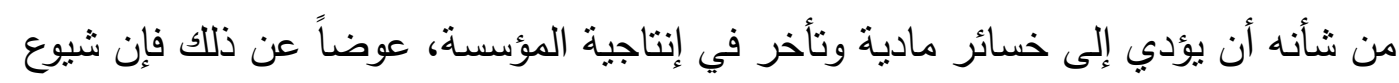

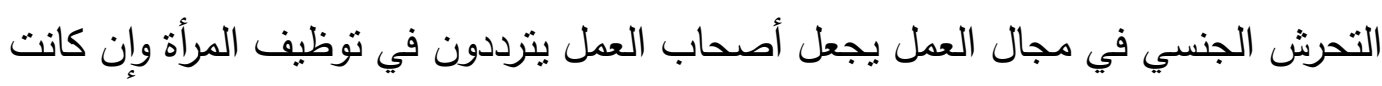

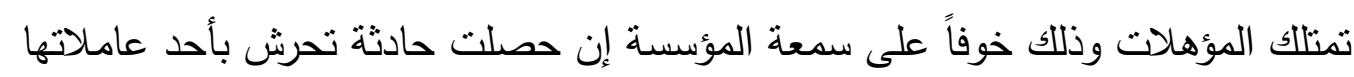
بالإضافة إلى الخوف من تسربهن.

حددت منظمة العمل الدولية (منظمة العمل الدولية، الف 2005) آثار التحرش الجنسي بالمرأة

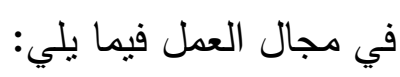
• استقالة الضحية بدلاً من الاستمرار في العمل خشية التعرض للتحرش. •تقييم مهني متحيز أو توصيات مهنية سيئة. تخفيض المرتبة أو النقل أو الصرف أو النقليل من فرص التدريب أو فقدان فرص الترقية. خلق بيئة عمل ضاغطة تقود الضحية للإصابة بأمراض جسدية ونفسية. شعور الضحية بالإهانة والرفض. الإضرار بمستقبل الضحية المهني بوضع تقرير سيئ أو توصية سيئة. 
- جيدتز ، أنتوني(2006). مقدمة نقدية في علم الاجتماع، القاهرة ؛الطبعة الثانية، ترجمة

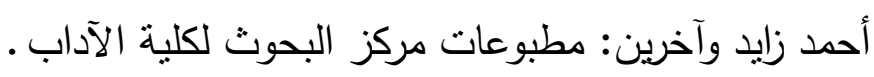

- أبوصالح،عنان (2012).مفهوم وتحليل ظاهرة العنف الجنسي،الناصرة:المركز العربي

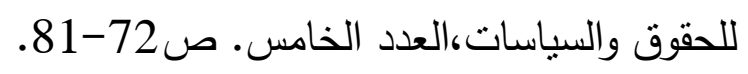
- جمعة،مجدي محمد (2013).العنف ضد المرأة بين التجريم وآليات المواجهة،القاهرة:وزارة الداخلية. - حسنرشا محمد(2008).التحرش الجنسي من المعاكسات الكلامية حتى الإنى الاغتصاب.بحث علمي منشور .مصر :المركز المصري لنؤون المرأة. - سبيتان،فتحي ذياب (2012).قضايا عالمية معاصرة.الرياض:الجنادرية للنشر والتوزيع. - طريف، شوقي وآخرون(2004).التحرش الجنسي بالمرأة العاملة، بحث علمي منشور بمجلة كلية الآداب جامعة بني سويف-العدد السابع-أكتوبر • - عبادة،ديحة أحمد وأبو دوح خالد كاظم(2007).الأبعاد الاجتماعية للتحرش الجنسي في الحياة اليومية،مصر :جامعة سوهاج. - عبداللهمنى محمود (2013).الأبعاد الاجتماعية والثقافية للتحرش الجنسي بالمرأة،القاهرة:المكتب العربي للمعارف. - قطب،محد علي(2008)التحرش الجنسي أبعاد الظاهرة وآليات المواجهة،القاهرة:مكتبة المجلس القومي للمرأة.

- فرجهريف وآخرون (2004).التحرش الجنسي بالمرأة العاملة:بحث علمي منشور بمجلة كلية الآداب جامعة بني سويف، 7آخرون (19: 19-79.

- فايد،سوسن(2004).حول أزمة القيم المجتمع المصري بين النمط المثالي والممارسة الفعلية، المجلة الاجتماعية القومية، المركز القومي للبحوث الاجني الاجتماعية والجنائية، القاهرة ، العدد2.

- العواودة،أمل سالم (2009).العنف ضد المرأة في القطاع الصحي،دارسة علمية منشورة:دار اليازوري العلمية. - العمر ، معن خليل (2015).علم اجتماع الجندر .فلسطين:دار الثروق 


$$
\text { - السيد، ابراهيم جابر (2012).المشكلات الاجتماعية داخل المجتمع العربي. }
$$

- نييه، نسرين عبدالحميد (2007).الإجرام الجنسي، الإسكندرية:دار الجامعة الجديدة. - محدهمحمود فتحي(2010).العوامل المؤدية للتحرش الجنسي ودور الخدمة الاجتماعية في التعامل معها،دراسة علمية منشورة على شبكة الانترنت ،مصر :جامعة الفيوم. - منظمة العمل الدولية (2005).تعزيز المساواة بين الجنسين، الدكتب الإقليمي للدول العببة،بيروت.

- عامر، طارق عبد الرؤوف والمصري،إيهاب عيسى (2014). العنف ضد المرأة مفهومه أسبابه أنشكاله:مؤسسة طيبة علنش للنشر والتوزيع.

- درويش، محمد فهيم(2008).الجرائم الجنسية الغريزة الجنسية وتأثثرها على ارتكاب الجريمة في ضوء الثريعة والقانون:دار النور للنشر والنوزيع.

- الإساءة إلى المرأة ، هبة محمد علي حسن، 2003 ، مكتبة الأنجلو المصرية - موسى،دعد (2008).دور المرأة العربية كفرص في المجالات القانونية الإدارية

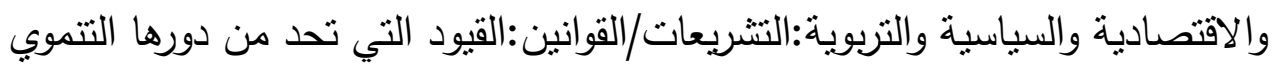

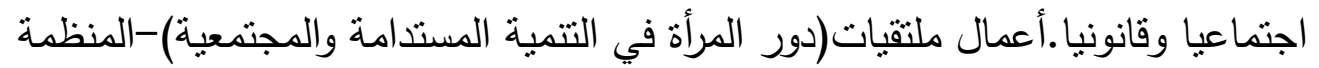

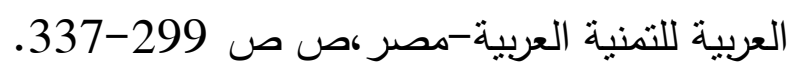

- مكتب العمل الدولي(2009) -القرارات التي اعتمدها مؤتمر لعمل الدولي في دورته الثامنة والتنعين.

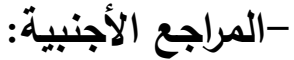

Aware(2008) Subcommittee Sexual harassment in the workplace , Research study About Place a sexual act Harassment Singapore. Human Rights(2012):Cultivating Fear The Vulnerability of Immigrant Farmworkers in the US to Sexual Violence and Sexual Harassment Cultivating Fear, Human Rights May. Sadrddin, M(2013) Sexual Harassment at Workplace in Pakistan- Issues and Remedies about, the Global Issue at Managerial Sector , Cordoba University, Journal of Managerial Sciences, Vol. 125 No. 1

Ficher,N(2003): LaPsychologieViolencesSociales.dunod,paris.

Karge, $\mathrm{R}(2002)$ : violence against women in the workplace in kenya Assessment of Workplace Sexual Harassment in the Commercial - 
Agriculture and Textile Manufacturing Sectors in Kenya International Labor Rights Fund.

Fichergustave Nicolas (2003) la psychologie des violencessocials, dunod.paris.

Hersch,J (2015): Sexual harassment in the workplace,USA, andIZA,German,VanderiltUnivsity. 